\title{
Millimeter Wave Holographical Inspection of Honeycomb Composites
}

\author{
J.T. Case ${ }^{l}$, S. Kharkovsky ${ }^{1}$, R. Zoughil ${ }^{l}$, G. Steffes ${ }^{2}$ and F.L. Hepburn ${ }^{3}$ \\ ${ }^{1}$ Electrical and Computer Engineering Department \\ Applied Microwave Nondestructive Testing Laboratory (amntl) \\ University of Missouri-Rolla \\ Rolla, Mo 65409 \\ ${ }^{2}$ Air Force Research Laboratory \\ Wright-Patterson Air Force Base \\ Wright-Patterson, $\mathrm{OH} 45433$ \\ ${ }^{3}$ NASA George C. Marshall Space Flight Center \\ Marshall Space Flight Center, AL 35812
}

Contact author e-mail: zoughir@umr.edu

\section{ABSTRACT}

Multi-layered composite structures manufactured with honeycomb, foam or balsa wood cores are finding increasing utility in a variety of aerospace, transportation, and infrastructure applications. Due to the low conductivity and inhomogeneity associated with these composites standard nondestructive testing (NDT) methods are not always capable of inspecting their interior for various defects caused during the manufacturing process or as a result of in-service loading. On the contrary, microwave and millimeter wave NDT methods are well-suited for inspecting these structures since signals at these frequencies readily penetrate through these structures and reflect from different interior boundaries revealing the presence of a wide range of defects such as disbond, delamination, moisture and oil intrusion, impact damage, etc. Millimeter wave frequency spectrum spans $30 \mathrm{GHz}-300 \mathrm{GHz}$ with corresponding wavelengths of $10-1 \mathrm{~mm}$. Due to the inherent short wavelengths at these frequencies, one can produce high spatial resolution images of these composites either using real-antenna focused or syntheticaperture focused methods. In addition, incorporation of swept-frequency in the latter method (i.e., holography) results in high-resolution three-dimensional images. This paper presents the basic steps behind producing such images at millimeter wave frequencies and the results of three specific homeycomb composite panels (two flat and one curved) will be demonstrated at Q-band (33-50 GHz). In addition, these results will be compared to others using computed tomography and near-field microwave and millimeter wave methods. 


\title{
MILLIMETER WAVE HOLOGRAPHICAL INSPECTION OF HONEYCOMB COMPOSITES
}

\author{
J.T. Case ${ }^{1}$, S. Kharkovsky ${ }^{1}$, R. Zoughi ${ }^{1}$, G. Steffes ${ }^{2}$, and F.L. Hepburn ${ }^{3}$ \\ 'Applied Microwave Nondestructive Testing Laboratory (amntl) \\ Electrical and Computer Engineering Department \\ University of Missouri-Rolla \\ Rolla, MO 65409 \\ ${ }^{2}$ Air Force Research Laboratory (AFRL) \\ Materials and Manufacturing Directorate \\ 2230 Tenth Street, Ste. 1 \\ Wright-Patterson, $\mathrm{OH} 45433$ \\ ${ }^{3}$ NASA George C. Marshall Space Flight Center, \\ MSFC, AL 35812
}

\begin{abstract}
Multi-layered composite structures manufactured with honeycomb, foam or balsa wood cores are finding increasing utility in a variety of aerospace, transportation, and infrastructure applications. Due to the low conductivity and inhomogeneity associated with these composites standard nondestructive testing (NDT) methods are not always capable of inspecting their interior for various defects caused during the manufacturing process or as a result of in-service loading. On the contrary, microwave and millimeter wave NDT methods are well-suited for inspecting these structures since signals at these frequencies readily penetrate through these structures and reflect from different interior boundaries revealing the presence of a wide range of defects such as disbond, delamination, moisture and oil intrusion, impact damage, etc. Millimeter wave frequency spectrum spans $30 \mathrm{GHz}-300 \mathrm{GHz}$ with corresponding wavelengths of $10-1 \mathrm{~mm}$. Due to the inherent short wavelengths at these frequencies, one can produce high spatial resolution images of these composites either using real-antenna focused or synthetic-aperture focused methods. In addition, incorporation of swept-frequency in the latter method (i.e., holography) results in high-resolution three-dimensional images. This paper presents the basic steps behind producing such images at millimeter wave frequencies and the results of two honeycomb composite panels are demonstrated at Q-band (33-50 $\mathrm{GHz}$ ). In addition, these results are compared to previous results using X-ray computed tomography.
\end{abstract}

Keywords: Honeycomb Composites, Millimeter Waves, Holography

PACS: $81.70 . \mathrm{Ex}$, 84.40.-x, 77.84.Lf, 07.60Hv, 68.37.Uv

\section{INTRODUCTION}

Microwave and millimeter wave nondestructive testing (NDT) techniques have been effectively used for inspection of a wide variety of complex composite structures. These investigations have primarily used near-field [1-9] or focusing lens [9-10] techniques for testing, evaluation, material characterization and imaging. The ability of 
these signals to readily penetrate inside of composite structures, their relatively short wavelengths and the fact that near-field and focusing lens inspection produces high spatialresolution images makes these techniques extremely attractive, viable and in some cases unique for the purpose of composite inspection. There are other advantageous attributes that these techniques possess and the entire list along with pertinent discussions can be found in $[1,9]$.

There are two significant attributes associated with these signals that make them very attractive for producing synthetic-aperture and holographical images; namely, the relatively wide bandwidth associated with various millimeter wave bands and the ability to perform coherent measurements (e.g., availability to measured magnitude and phase referenced to a known plane). The latter provides for the necessary requirement of coherent signal addition when producing a synthetic-aperture image, which inherently possesses high spatial resolution [11-12]. The former provides for high depth resolution (similar to a narrow pulse in time domain) and hence allows for holographic algorithms to be used to produce a high-resolution three-dimensional (3D) image of an object or a composite structure [12-14]. In addition to producing a high-resolution 3D image, one can also slice the 3D image at various depths (depending of the available signal bandwidth) and hence create image slices similar to those produced by X-ray computed tomography. Microwave holography, as described above has recently been successfully used for acreage heat tile and spray-on-foam-insulation (SOFI) imaging of the Space Shuttle structural components [14].

To describe the method simply, a compensation of the round trip phase is performed for wave signals originating from points on a plane to an arbitrary located target using angular spectrum decomposition. This requires a swept-frequency measurement of the complex microwave reflection coefficient over a plane, which for the purpose of this investigation, was taken using an open-ended waveguide probe over the Q-band (33-50 $\mathrm{GHz}$ ) frequency range. The resulting dataset is a volumetric representation of the specimen and can be graphically illustrated as such. The spatial resolution is approximately one quarter of the mid-frequency wavelength and the range resolution is $c / 2 B$, where $c$ is the speed of light and $B$ is the transmitted signal bandwidth, which in this case is $17 \mathrm{GHz}$ [1213]. For a signal originating at a point target, signals add constructively otherwise the signals add destructively resulting in a high-resolution image. For processing purposes, it is assumed that the wave is not delayed as it propagates through air or the honeycomb composite sample. This assumption is acceptable since the interior of the composites is made of honeycomb with a dielectric constant close to that of free-space. Therefore, image processing is used to aid in finding reflections occurring at air to honeycomb interfaces.

\section{DESCRIPTION OF PANELS AND PREVIOUS RESULTS}

Two honeycomb composites panels (1"-thick and 0.5 "-thick) were evaluated. Each panel had one side bonded with a thin glass fiber reinforced polymer (GFRP) laminar skin and the other side bonded with a thin multi-directional carbon fiber reinforced polymer (CFRP) skin. The panels appear to be produced with several embedded defects made out of thin polymer sheets (i.e., Teflon tape, plastic, paper, etc.) and missing honeycomb/skin material. The embedded defects primarily represented planar disbonds, crushed core, and delaminations at various heights within the thickness of the panels and with different shapes. The first panel (Panel \#1) was a 1"-thick honeycomb sample produced by stacking two 0.5 "-thick honeycomb layers on top of one another with a mid-thickness composite septum separating the honeycomb layers. The second panel composite (Panel \#2) similarly 
was manufactured except that it had a single layer of 0.5 "-thick honeycomb core [15].

These panels were used in an earlier investigation for the purpose of comparing the ability of several NDT methods, including near-field millimeter waves, X-ray computed tomography $(\mathrm{CT})$, shearography and through-transmission ultrasound, for inspecting these panels. The results indicated that X-ray CT and near-field millimeter wave NDT methods scored very high in terms of detecting the most number of inserts while providing high spatial resolution images, as shown in Table 1 . In addition, the X-ray CT provided very high depth resolution as well as image slices of the samples [15]. Thus, in the investigation we will focus on comparing the millimeter wave holographical results with those from the $\mathrm{X}$-ray CT.

Table 1. Summary of detection and resolution attributes of the four NDT methods [15].

\begin{tabular}{|c|c|c|c|}
\cline { 2 - 3 } \multicolumn{1}{c|}{} & \multicolumn{2}{|c|}{ Detection (Number of Flaws) } & \multirow{2}{*}{ Lateral Resolution } \\
\cline { 2 - 4 } & Panel \#1 & Panel \#2 & High \\
\hline \hline X-Ray CT & 8 & 7 & High \\
\hline Near-Field Millimeter Wave & 6 & 7 & Low \\
\hline Shearography & 4 & 6 & Moderate \\
\hline Through-Transmission UT & 4 & 5 & \\
\hline
\end{tabular}

\section{RESULTS}

Figures 1 and 2 show several X-ray CT slices of the two panels obtained from the previous investigation [15]. These results clearly show the relative size and location of the various embedded flaws in these samples. Figure $3 \mathrm{a}$ shows the picture of the measurements setup with the Q-band open-ended waveguide probe held approximately 22 $\mathrm{mm}$ above panel \#1. Since the bottom skin of this and panel \#2 is made of multidirectional CFRP sheet, millimeter wave reaching the bottom skin are reflected back towards the

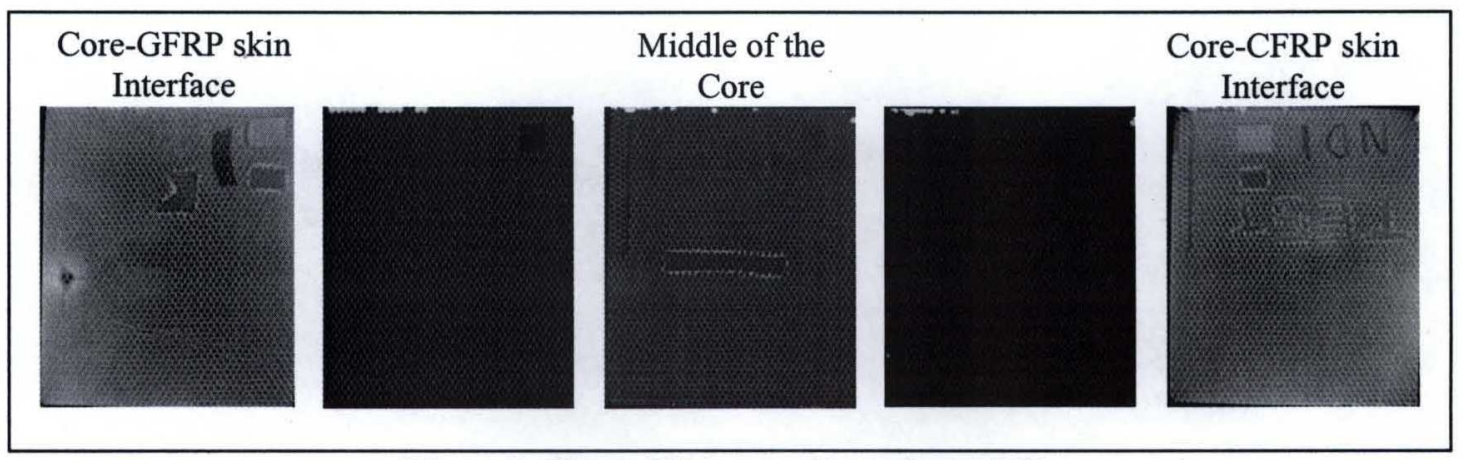

Figure 1: X-ray CT image slices of panel \#1.

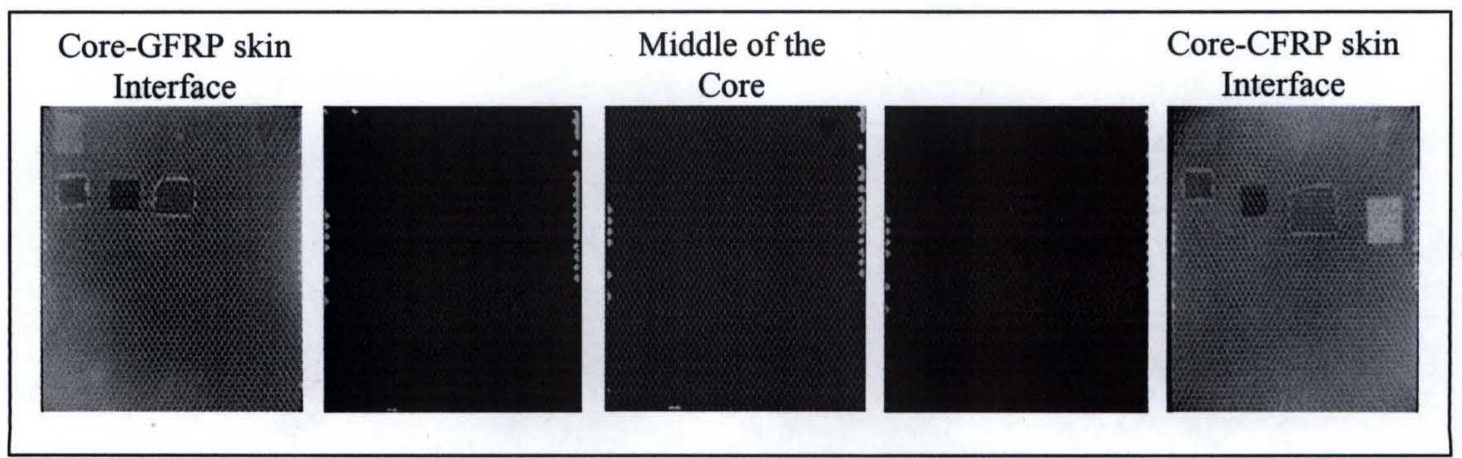

Figure 2: X-ray CT image slices of panel \# 2. 
probe (i.e., this sheet acts as a very good reflector of millimeter wave signals). Figure $3 \mathrm{~b}$ shows a 3D-view of panel \#1 showing several of the flaws under the top skin. This 3D image (hologram) is an impressive demonstration of the utility of millimeter wave holography for thick composite inspection. Figures 4a-c show three different slices of the hologram at three different depths within panel \#1; namely, the region immediately corresponding to the top of the panel, $8 \mathrm{~mm}$ below that and then $6 \mathrm{~mm}$ deeper, respectively. There are several important observations that must be made with respect to the results shown in Figure 4. The spatial resolution associated with this holography technique is approximately half of the dimension of the waveguide probe aperture (in each direction). Given that at Q-band the aperture dimension of the waveguide probe is $5.7 \mathrm{~mm}$ by $2.8 \mathrm{~mm}$, one can see the high spatial resolution associated with images in Figures $3 \mathrm{~b}$ and $4 \mathrm{a}-\mathrm{c}$. The spatial resolution associated with these images provides similar image interpretation capability as those images obtained using X-ray CT. The transmitted signal bandwidth for these measurements was $17 \mathrm{GHz}$. Therefore and as explained earlier, the depth resolution associated with these images is $\sim 8.8 \mathrm{~mm}$. This is clearly not as fine of a resolution as that obtained by the X-ray CT. Therefore, when considering the hologram slice images in Figure 4, flaws under the skin (Figure 4a) also appear in Figure 4b. However, it is important to note that at each depth the flaw associated with that depth looks much more focused and clear compared to the same flaw observed in slices as when looking at a slice less than a resolution depth away. Collectively these results show the tremendous capability and utility of millimeter wave holography for comprehensive 3D inspection of thick composite structures.

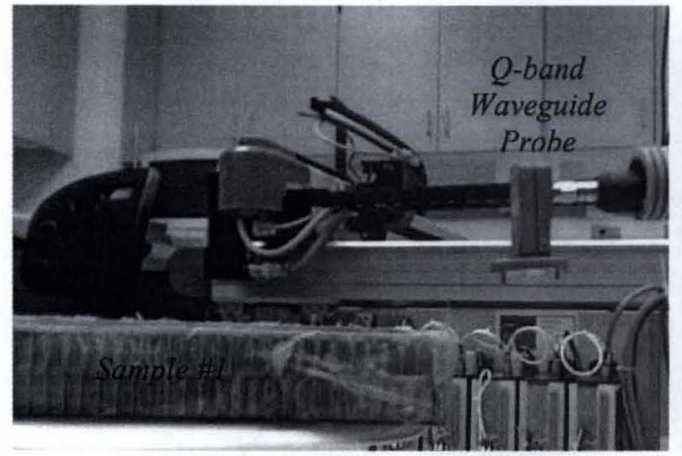

(a)

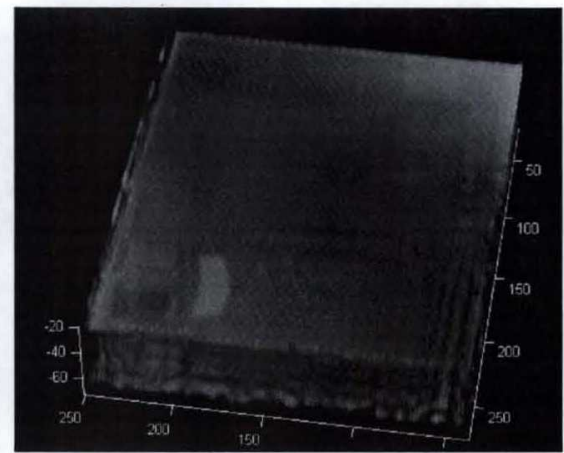

(b)

Figure 3: a) Measurement setup and b) 3D view (hologram) of panel \#1.

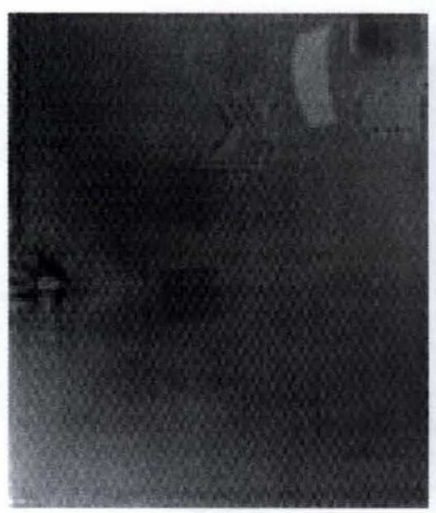

(a)

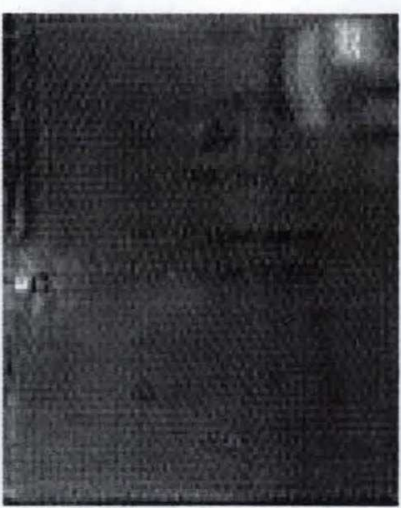

(b)

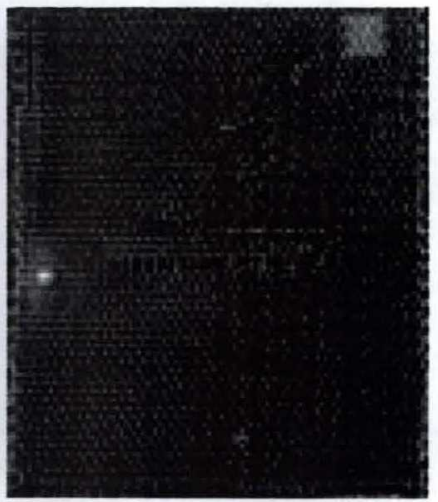

(c)

Figure 4: Hologram slices of panel \#1 at relative distances to the probe of a) $24 \mathrm{~mm}$, b) $32 \mathrm{~mm}$ and c) $38 \mathrm{~mm}$. 
Figure 5 shows the picture of the measurement set up for panel \#2. This panel was thinner than panel \#1. Therefore, the preceding discussions with respect to depth resolution apply even more to this panel. Figure 6a-c show three slices of the hologram of this panel, clearly showing the embedded flaws and the associated spatial resolution. The results show that even for this thinner panel, millimeter wave holography is a very useful imaging technique for evaluating interior characteristics of the panel.

\section{SUMMARY}

Millimeter wave holography is an effective and useful imaging techniques for evaluating interior characteristics of thick composite panels with honeycomb, balsa wood or foam cores. The large signal bandwidth associated with millimeter wave signals, the relatively small waveguide probe dimensions at these frequencies, along with available synthetic and holographical algorithms provides a great opportunity for an exciting area of imaging and nondestructive testing of composite structures. The results of two panels shown in this paper indicate that at Q-band $(33-50 \mathrm{GHz})$ the spatial resolution associated with the images is excellent (in the few $\mathrm{mm}$ range) for nondestructive testing purposes. In addition, the depth resolution associated with the images also provides ample information with respect to the depth at which an embedded flaw may exist. The results also provided similar information to those obtained by X-ray CT. However, there are several advantageous practical features associated with millimeter wave holographical imaging techniques, such as safety, portability, relatively low cost, weight and size that make them very attractive for practical nondestructive testing purposes.

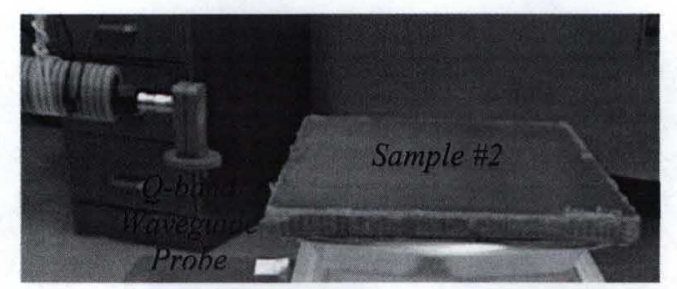

Figure 5: Measurement picture for panel \#2.

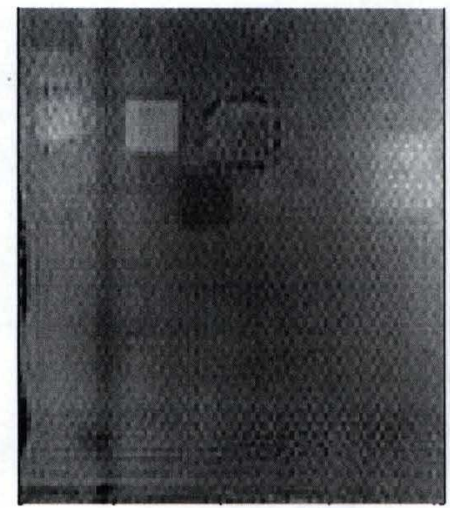

(a)

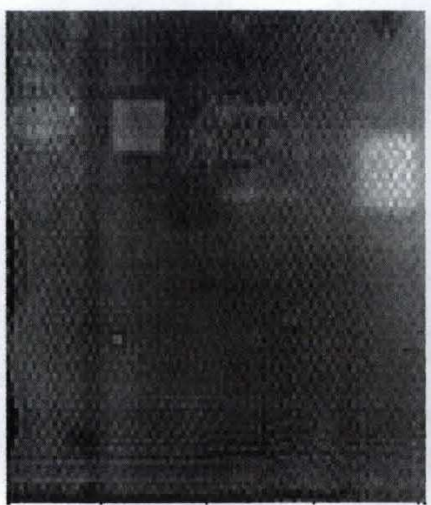

(b)

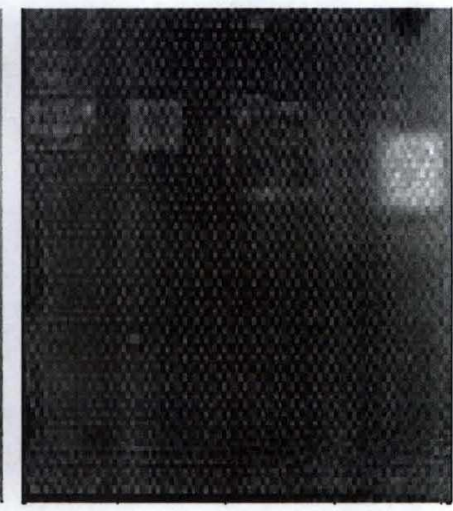

(c)

Figure 6: Hologram slices of panel \#2 at relative distances to the probe of a) $36 \mathrm{~mm}$, b) $38 \mathrm{~mm}$ and c) $40 \mathrm{~mm}$.

\section{ACKNOWLEDGEMENTS}

This work has been supported by a grant from the Air Force Research Laboratory (AFRL) under contract no. FA8650-04-C-5704, in conjunction with the Center for Aerospace Manufacturing Technologies (CAMT) at the University of Missouri-Rolla 
(UMR). We also would like to thank NASA Marshall Space Flight Center (MSFC) for providing the use a millimeter wave PNA for collecting the Q-band data and performing the experiments.

\section{REFERENCES}

1. R. Zoughi, Microwave Non-Destructive Testing and Evaluation, Kluwer Academic Publishers, the Netherlands, 2000.

2. S. Bakhtiari, S. Ganchev, N. Qaddoumi and R. Zoughi, IEEE Transactions on Microwave Theory and Techniques 42, pp. 389-395 (1994).

3. S. Gray, S. Ganchev, N. Qaddoumi, G. Beauregard, D. Radford and R. Zoughi, "Materials Evaluation 53, pp. 404-408 (1995).

4. N. Qaddoumi, S.I. Ganchev, G. Carriveau and R. Zoughi, Materials Evaluation 53, pp. 926-929 (1995).

5. N. Qaddoumi, R. Zoughi and G.W. Carriveau, Research in Nondestructive Evaluation 8, pp. 51-63 (1996).

6. N. Qaddoumi, T. Bigelow, R. Zoughi, L. Brown and M. Novack, Materials Evaluation 60, pp. 165-170 (2002).

7. R. Zoughi, J. Lai and K. Munoz, Materials Evaluation 60, pp. 171-177 (2002).

8. M. Abou-Khousa and R. Zoughi, IEEE Transactions on Instrumentation and Measurement, August (2007).

9. S. Kharkovsky and R. Zoughi, IEEE Instrumentation and Measurement Magazine 10, pp. 26-38 (2007).

10. S. Kharkovsky, J.T. Case, M. A. Abou-Khousa, R. Zoughi and F. Hepburn, IEEE Transactions on Instrumentation and Measurement 55, pp. 1250-1257 (2006).

11. D.M. Sheen, D.L. McMakin and T.E. Hall, IEEE Transactions on Microwave Theory and Techniques 49, pp. (2001).

12. F.T Ulaby, R.K. Moore and A.K. Fung, "Microwave Remote Sensing, Active and Passive" Vol. II, Artech House, Norwood, MA, 1986.

13. J.T. Case, "Microwave and Millimeter Wave Imaging using Synthetic Aperture Focusing and Holographical Techniques", Masters Thesis, Electrical and Computer Engineering Department, University of Missouri-Rolla, Rolla, MO, November 2005.

14. J.T. Case, S. Kharkovsky, R. Zoughi and F. Hepburn, "High Resolution Millimeter Wave Inspecting of the Orbiter Acreage Heat Tiles of the Space Shuttle", Proceedings of the IEEE Instrumentation and Measurement Technology Conference, \#7694, Warsaw, Poland, 2007.

15. M.A. Abou-Khousa, A. Ryley, S. Kharkovsky, R. Zoughi, D. Daniels, N. Kreitinger and G. Steffes, "Comparison of X-ray, Millimeter Wave, Shearography and ThroughTransmission Ultrasonic Methods for Inspection of Honeycomb Composites," in Review of Progress in QNDE, 26B, edited by D. O. Thompson and D. E. Chimenti, AIP Conference Proceedings vol. 894, American Institute of Physics, Melville, NY (2007), pp. 999-1006. 
Millimeter Wave Holographical Inspection of Honeycomb Composites 


\section{J.I. Base, S. Hharkorsky \& R. Zough}

Applied Microwave Nondestructive Testing Laboratory (amntl)

Electrical and Computer Engineering Department

University of Missouri-Rolla (UMR)

Rolla, MO 65409

(573) $341-4656$

zoughir@umr.edu

http://www.ece.umr.edu/amntl/ 


\section{Bollaborators}

\section{B. Stoffitos}

Air Force Research Laboratory

Wright-Patterson AFB, OH

\section{Fin Heplourn}

NASA Marshall Space Flight Center

MSFC, AL 


\section{AGknowledgment}

This work has been supported by a grant from the Air Force Research Laboratory (AFRL) under contract number FA8650-04-C-5704 in conjunction with the

Center for Aerospace Manufacturing Technologies (CAMT) at the University of Missouri-Rolla (UMR). 


\section{$\mu$-Wave \& mm-Wave Spectrum}

$300 \mathrm{MHz}$

$30 \mathrm{GHz}$

$300 \mathrm{GHz}$

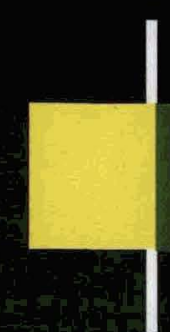

$1000 \mathrm{~mm}$
$\mu$-Waves

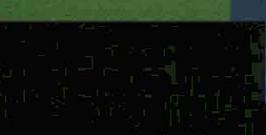

4. $10 \mathrm{~mm}$

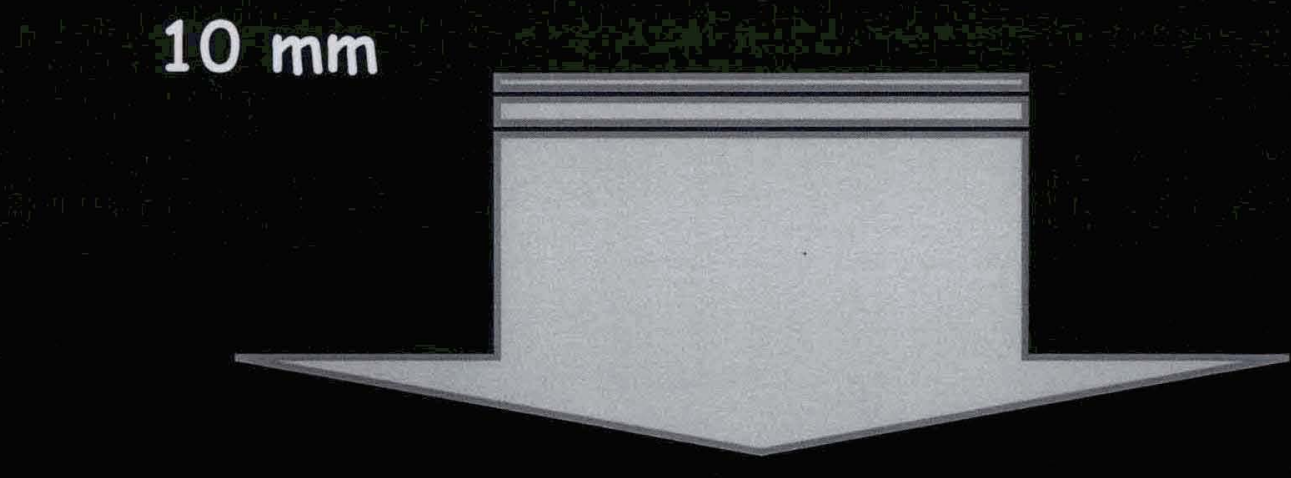

\section{mm-Waves}

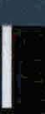

$\mathrm{K}-\mathrm{B}$ and $\mathrm{Ka}-\mathrm{Band}$

$V$-Band W-Band D-Band

18-26.5 26.5-40
50-75

75-110 110-170 


\section{Background}

- Radomes protect critical communications and radar antennas from exposure to adverse environmental conditions.

- They provide necessary aerodynamics for airborne systems.

Radomes must possess sufficient structural integrity to withstand severe environmental conditions and structural stresses.

- These stresses adversely affect the high frequency reflection and transmission properties of the radome thorough the generation disbonds, delaminations, impact damage or moisture permeation. 


\section{Batiground}

Radomes are in the family of thick stratified composite structures.

It is this stratified nature that renders radomes $\square$ transparent to high frequency signals.

Commonly section(s) of honeycomb core sandwiched between thin GRP skins.

- Control surfaces are similar in construction, but with significantly varying thickness throughout, having curved surfaces. 


\section{Atibulbes}

- These composites are in the family of low permittivity and low-loss dielectric materials.

$\mu$-wave and $\mathrm{mm}$-wave signals readily penetrate into low loss dielectrics.

- These signals are sensitive to dielectric property variations (i.e., boundaries).

$\checkmark$ Polarization, frequency, measurement parameter \& probe type diversity.

No need for a separate transmitter and receiver (i.e., mono-static systems).

$\checkmark$ Large available signal bandwidth. 


\section{Objective}

- Limited NDE techniques available for comprehensive inspection of these $\square$ low-loss $\square$ dielectric-based thick composite structures.

- Microwave and mm-wave NDE methods are well-suited for this purpose.

Implement sophisticated imaging techniques at these frequencies for 3D high-resolution imaging.

mm-wave synthetic aperture focusing and holographical methods are implemented here. 


\section{Synthetic Aperture Foensing}

A well-known imaging technique capable of producing high spatial resolution images (on the order of half of the antenna real dimensions and independent of antenna height).

- Based on phase correction as an antenna moves along a path [ uniform motion is not required.

- For example at $70 \mathrm{GHz}$ ( $V$-band) using openended rectangular waveguides or a small horn, images with resolution in the range of a few millimeters can be achieved. 


\section{Synthetic Aperture Foensing}

Antenna Motion Direction

- - - $>$

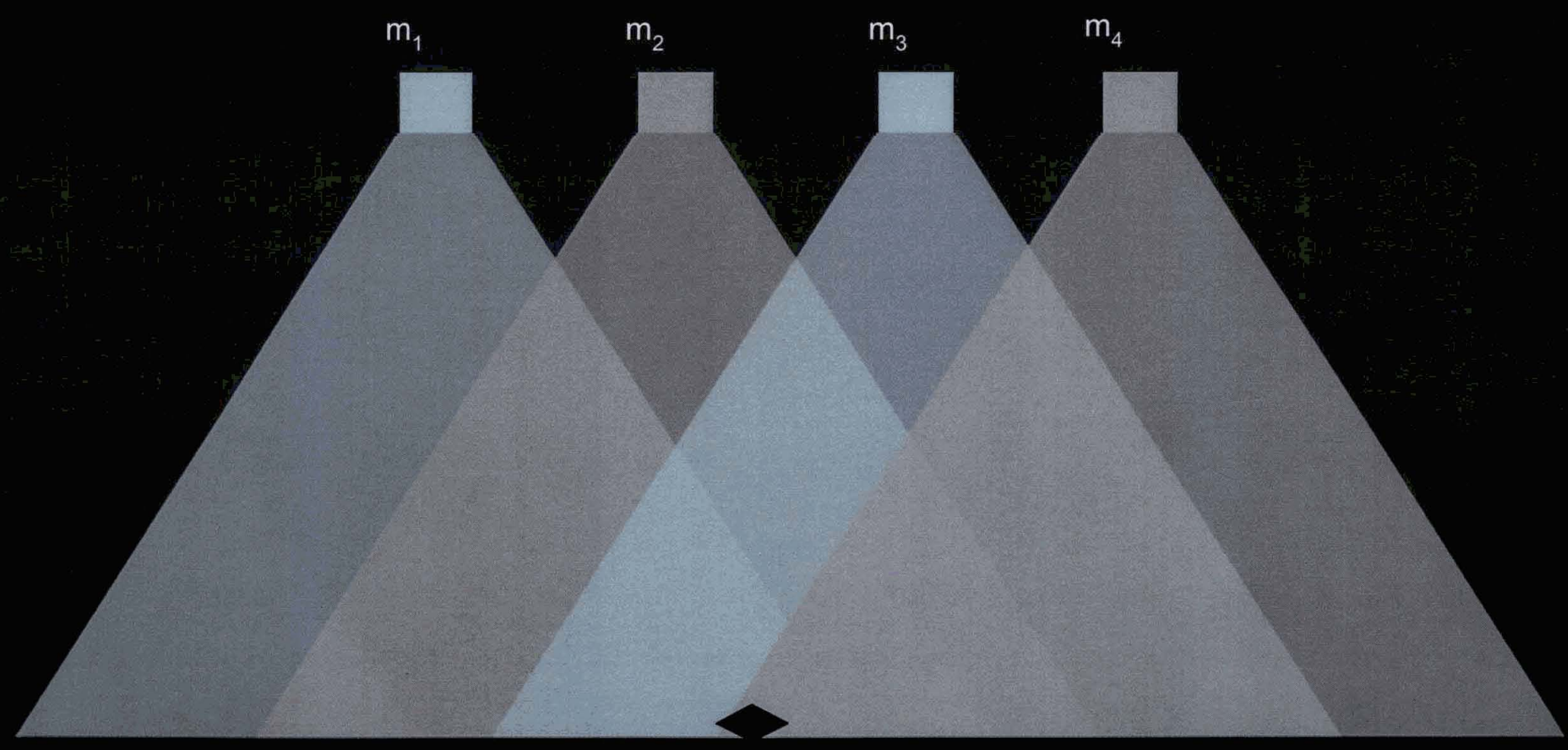




\section{Synthetic Aperture Focusing}

Antenna Motion Direction

$$
\text { - - - }>
$$

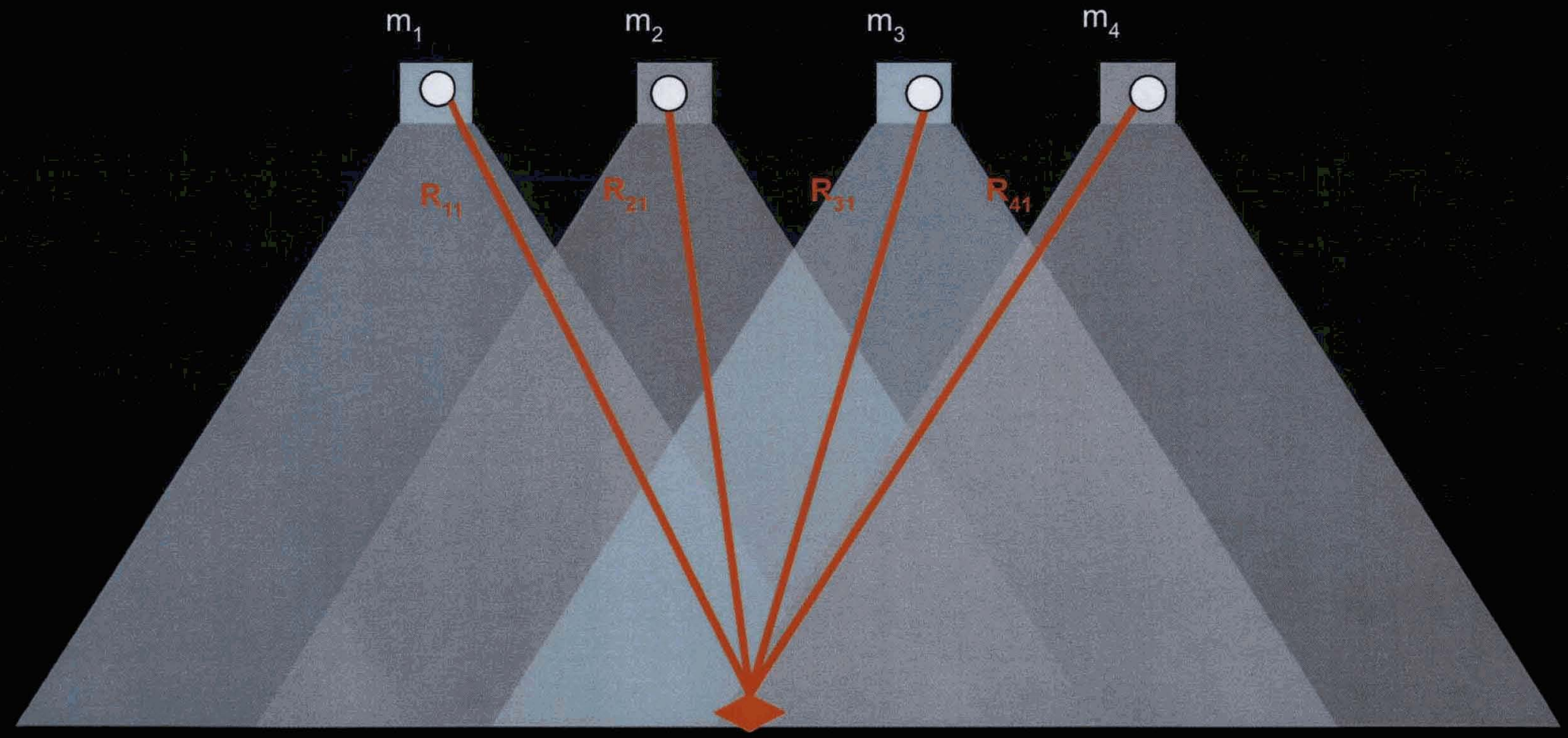




\section{Synthetic Aperture Focusing}

Antenna Motion Direction

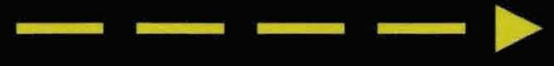

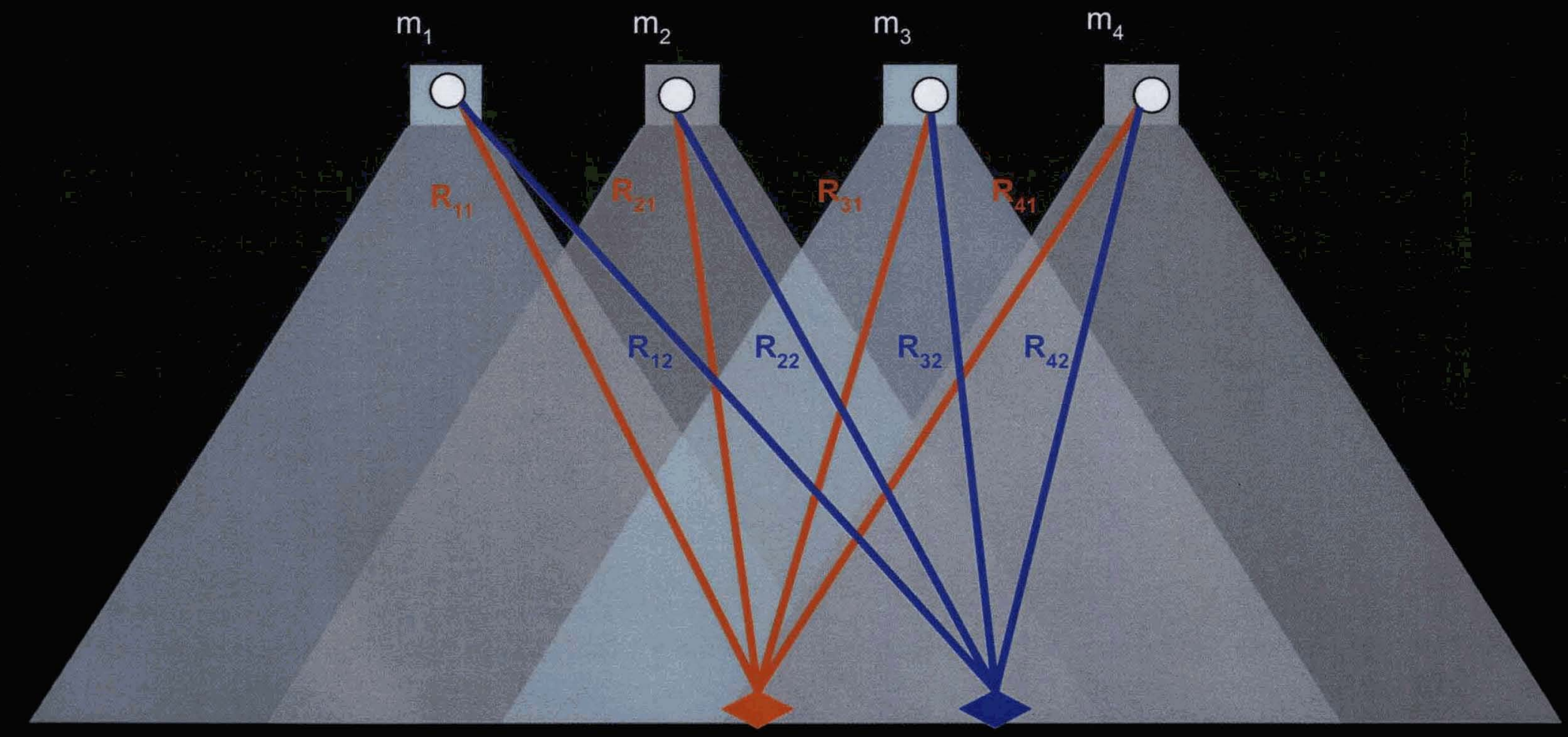

NASA

$$
s_{k}=\sum_{i=1}^{4} m_{i} \exp \left(j 2 \beta R_{i k}\right)
$$




\section{3 and 04 Panels}
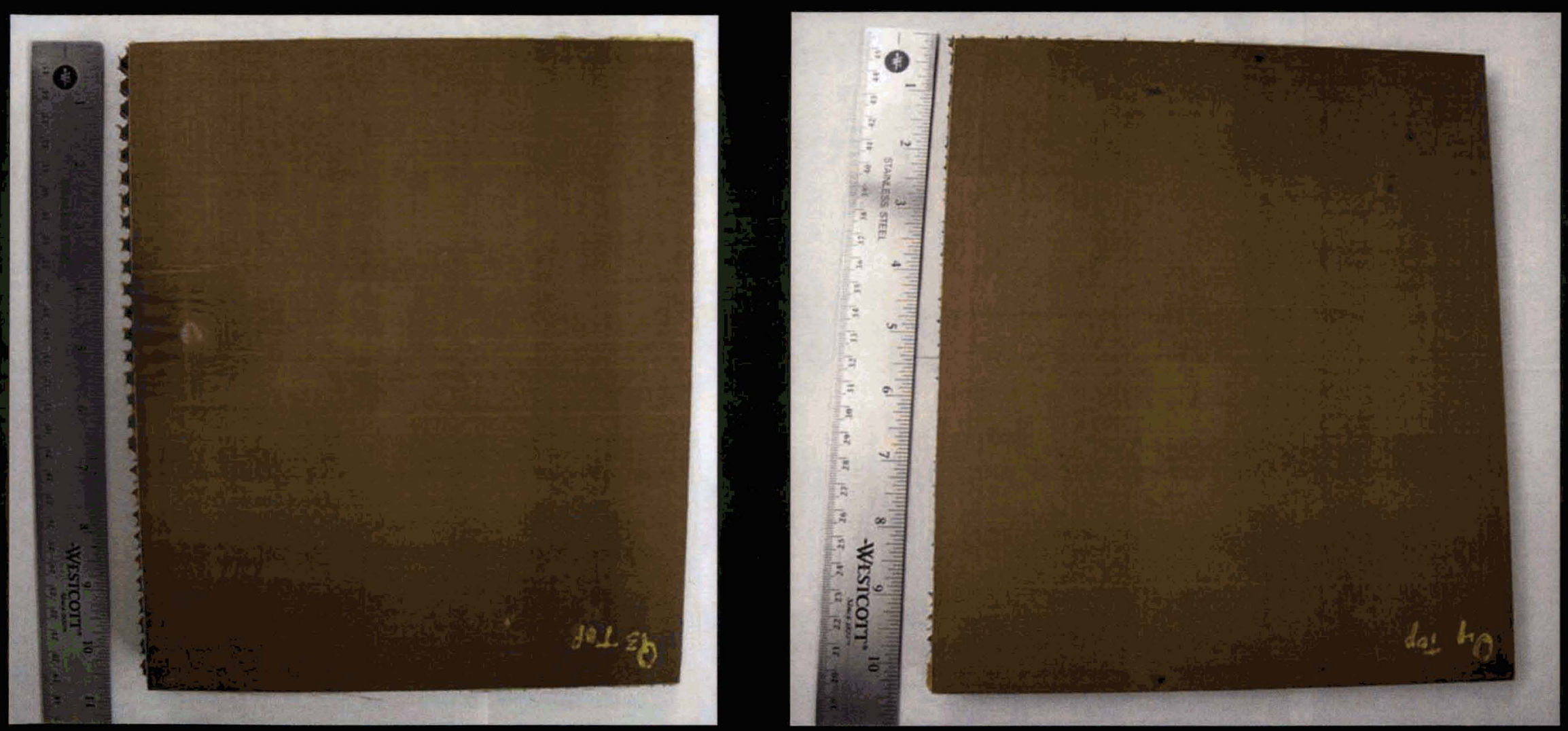


\section{X-iay Gomputed Tomography}

\section{Panel Q3}
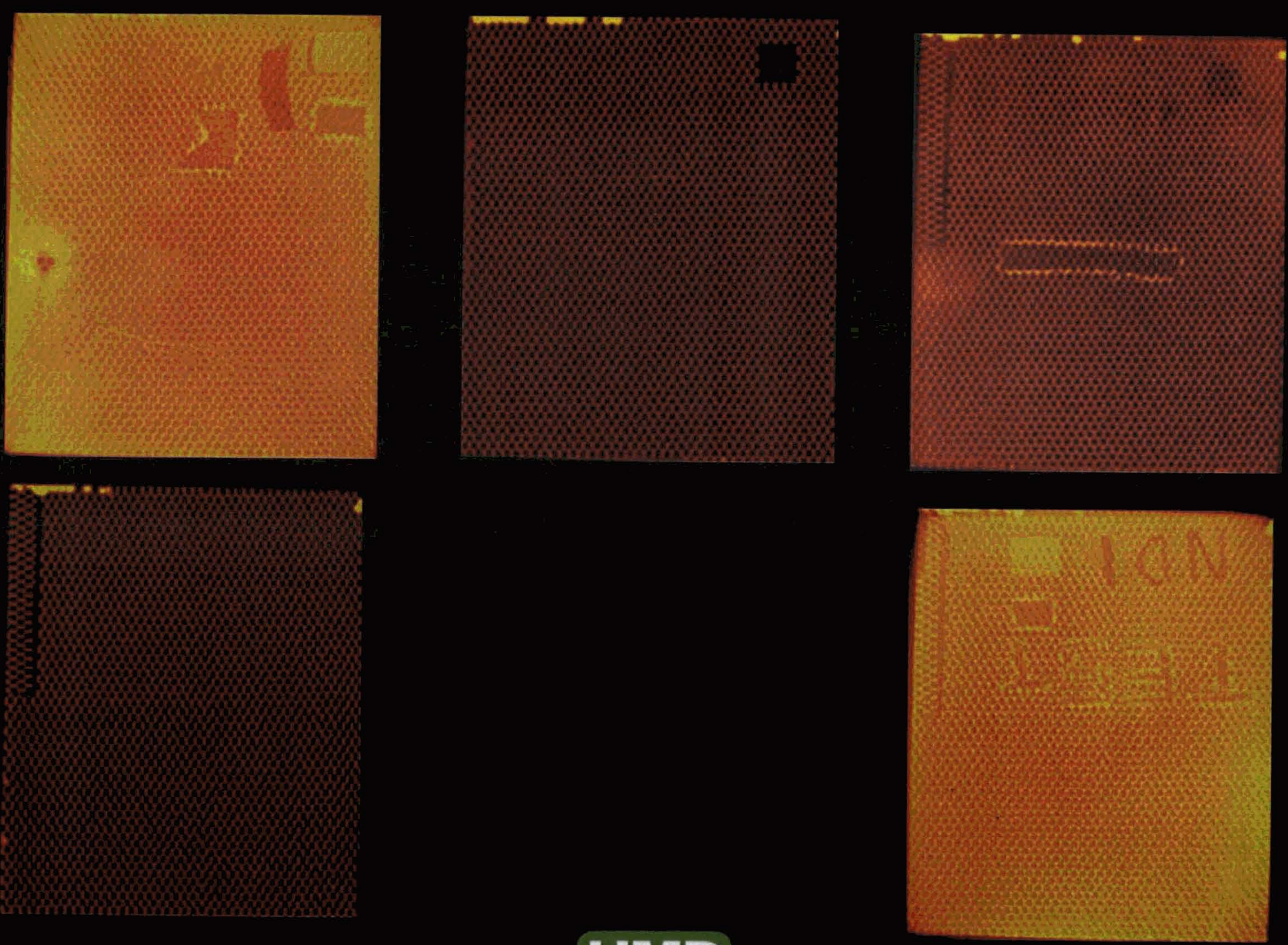


\section{X-Ray Gomputed Tomography}

Panel 04
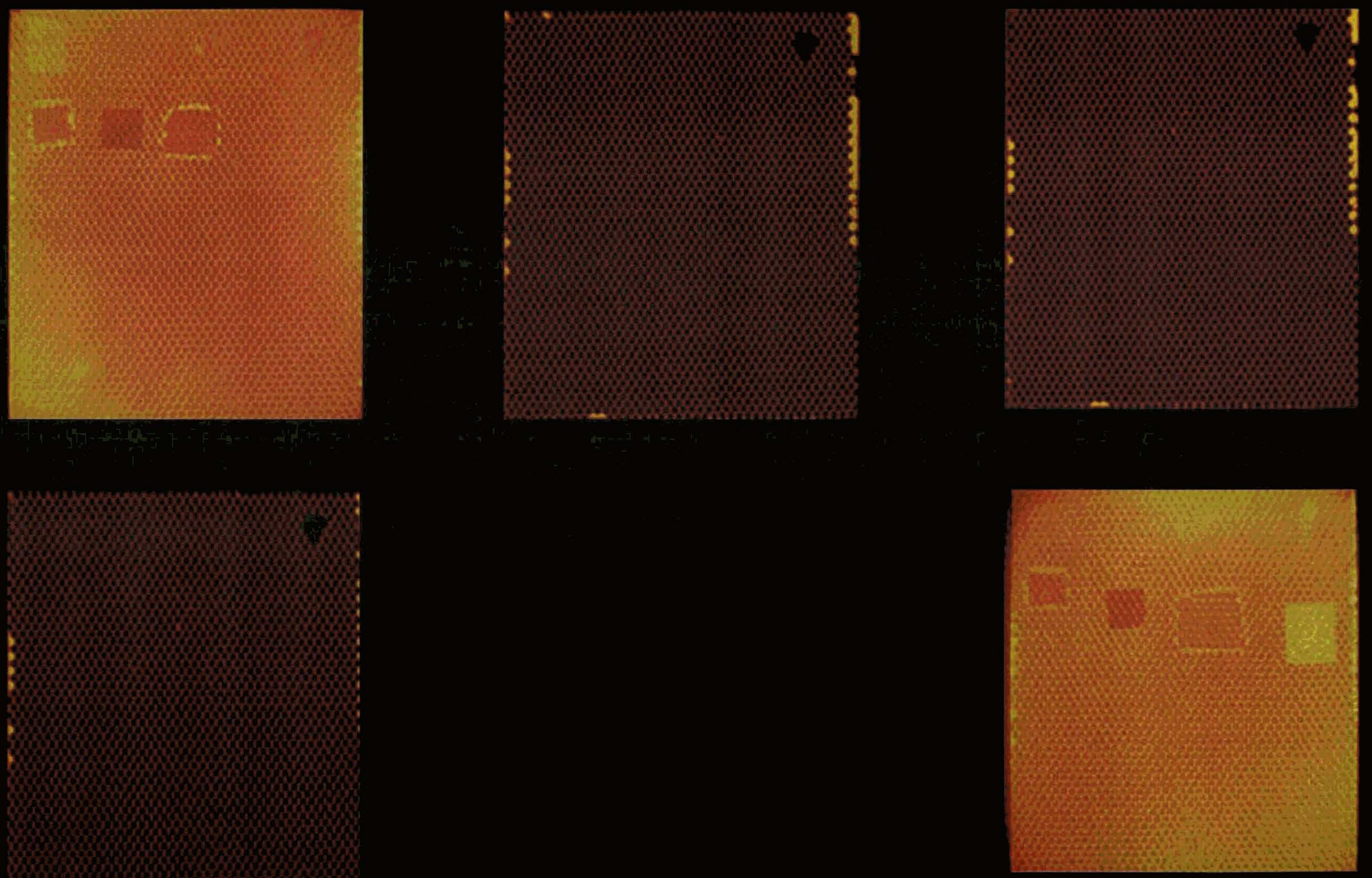


\section{Wear-Field mm-Wave}

Ka-band $(34 \mathrm{GHz}) \quad \mathrm{Ka}$-band $(36 \mathrm{GHz}) \quad \mathrm{V}$-band $(70 \mathrm{GHz})$
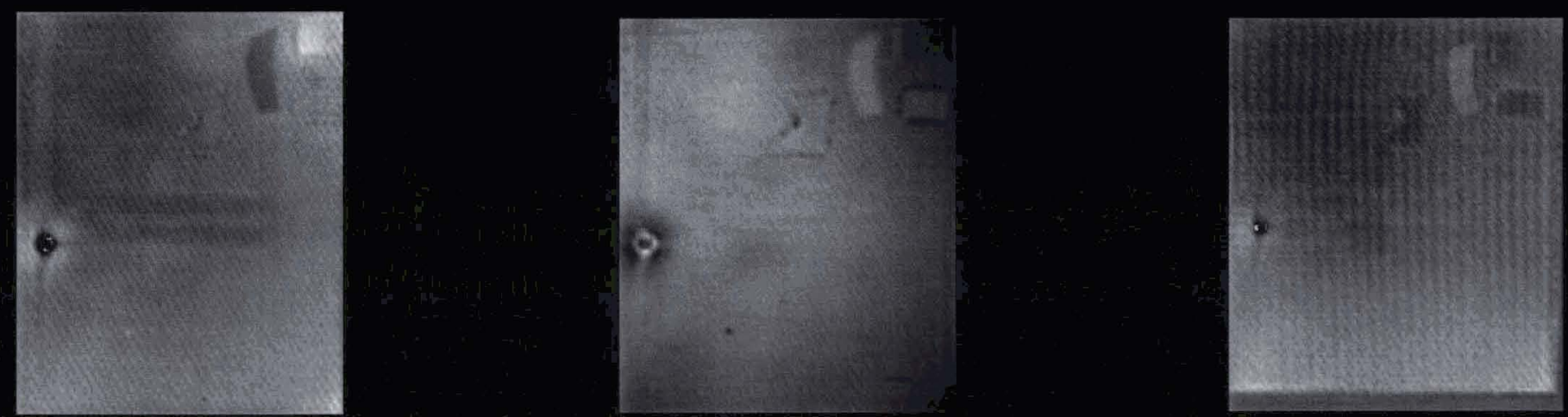

Panel Q3
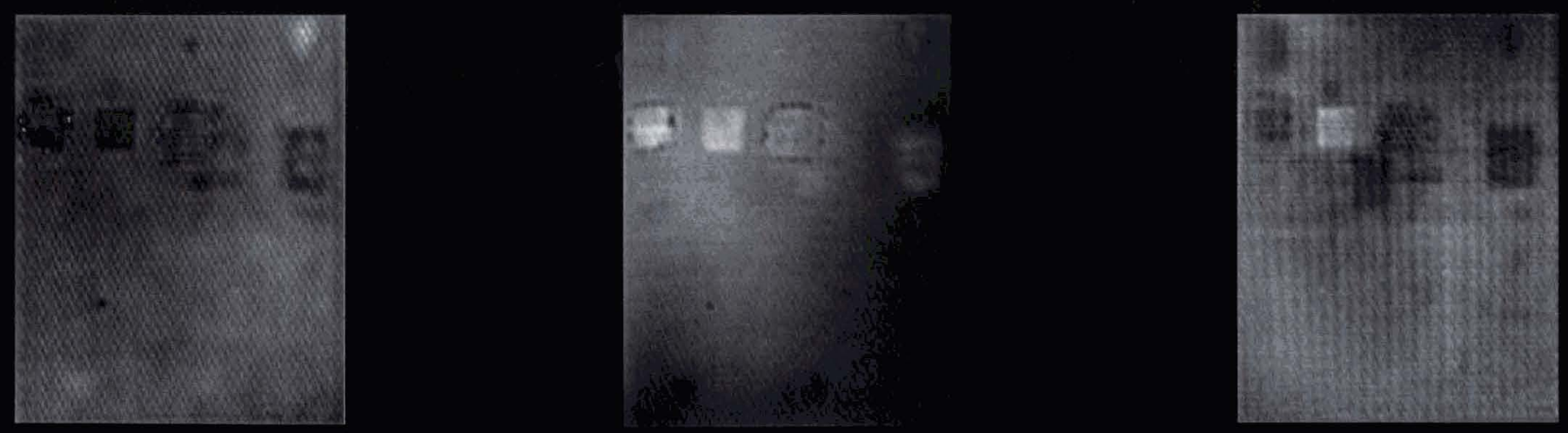

Panel 04 


\section{mm-Wave holography}

- Measurements at Q-band (33-50 GHz).

- Used the PNA at NASA MSFC.

Source power of $-5 \mathrm{dBm}$.

- Open-ended waveguide radiator located $\sim 20$ and 35 mm away.

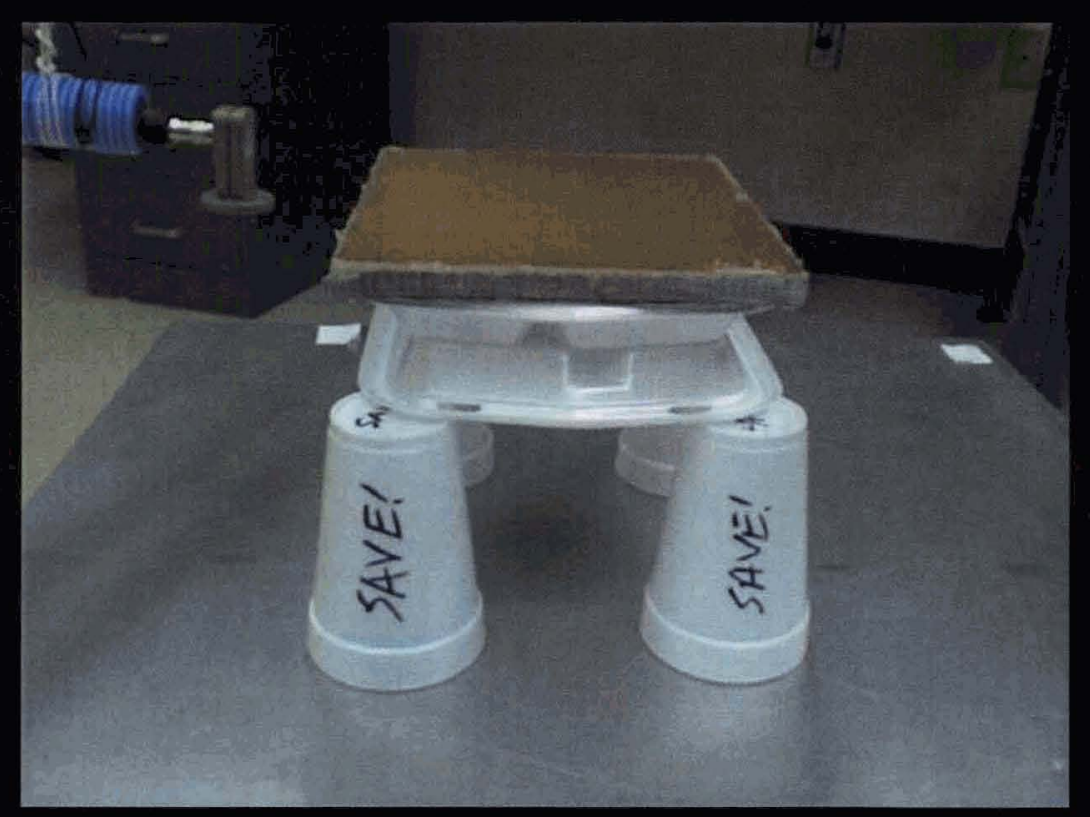




\section{mm-Wave Holography 13 Panel}

3D View

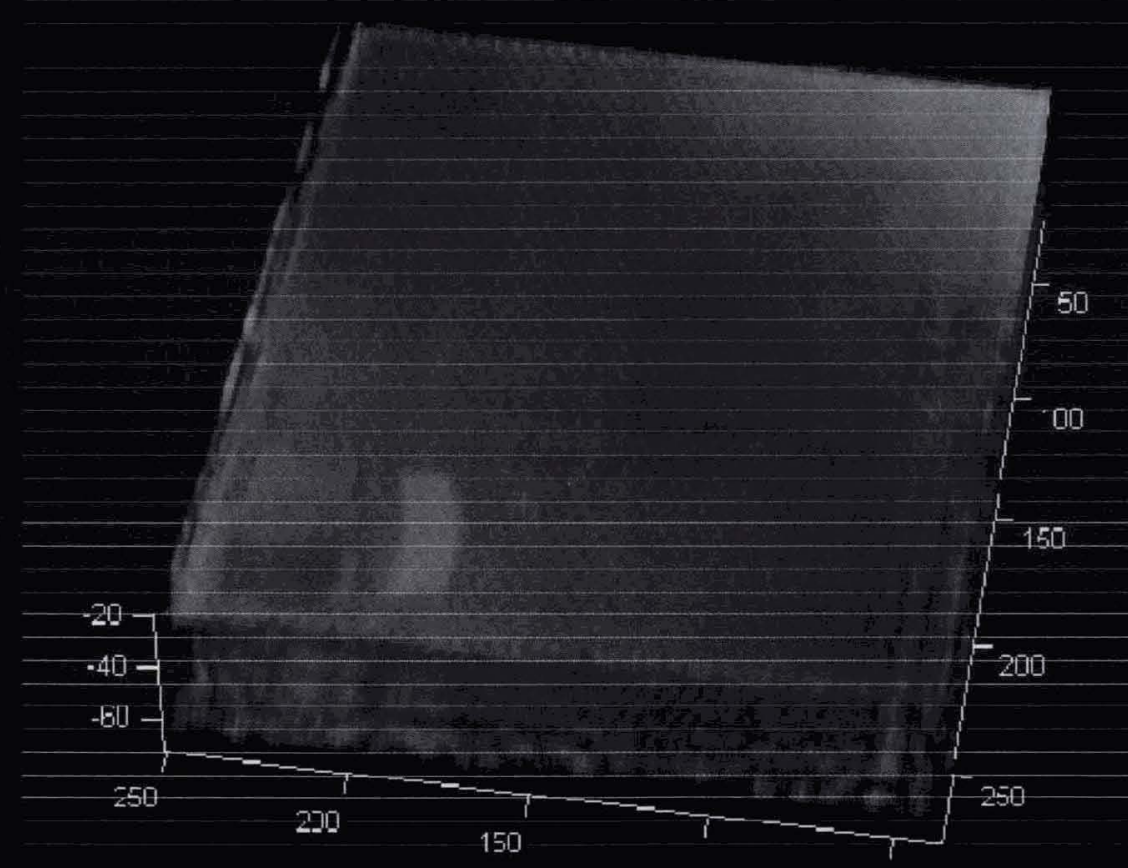

Top View

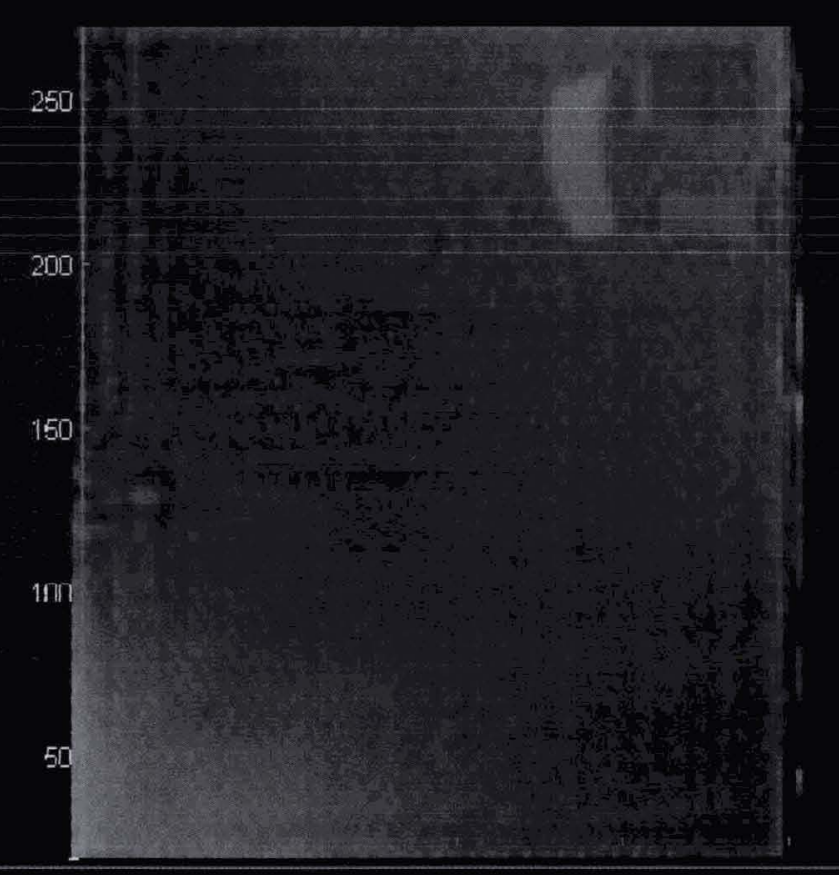




\section{Image SIices - 13 Panel}
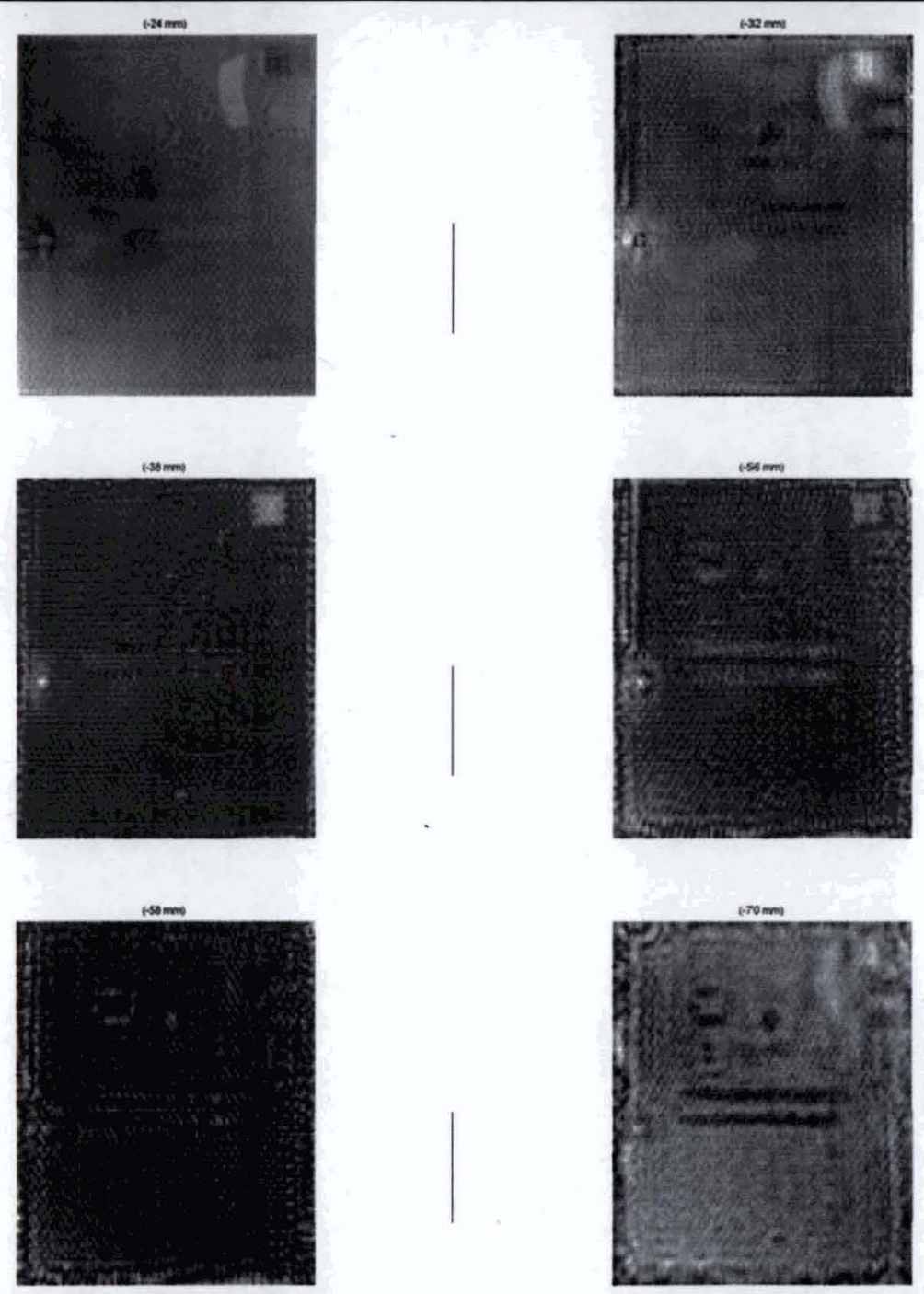

UMR 


\section{Image Slices - 04 Pancl}

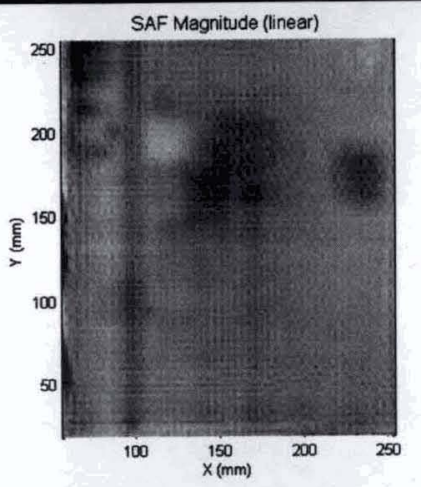

(-30 mm)
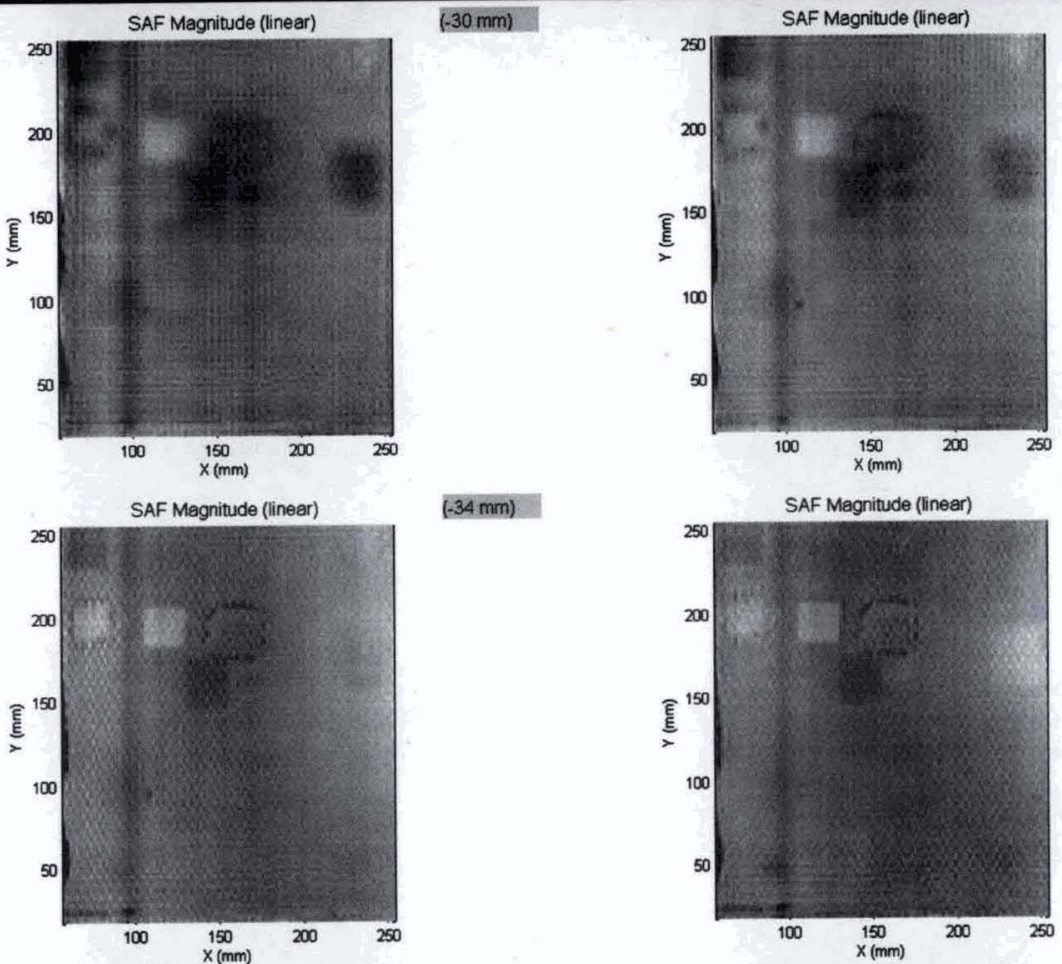

(-34 mm)

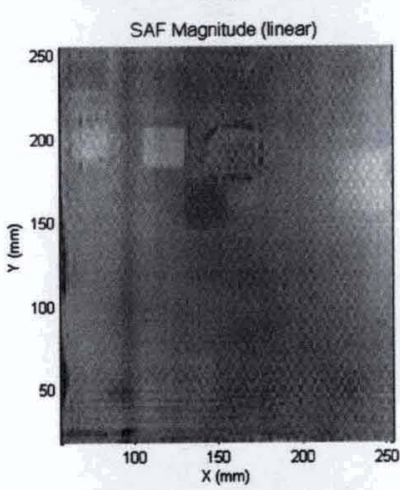

(-36 mm)

SAF Magnitude (linear)

$(-38 \mathrm{~mm})$
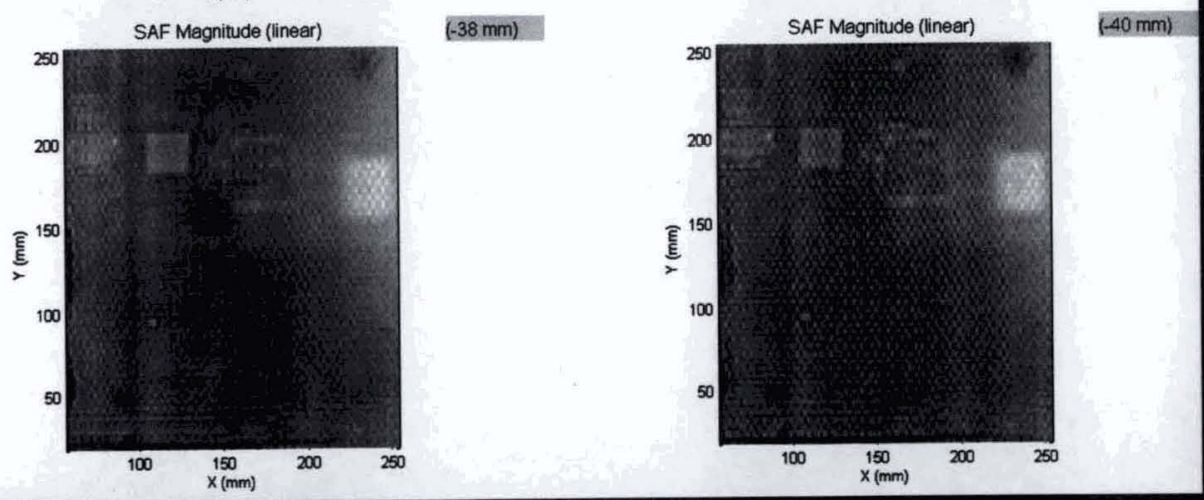


\section{Image Slices - 04 Panel}

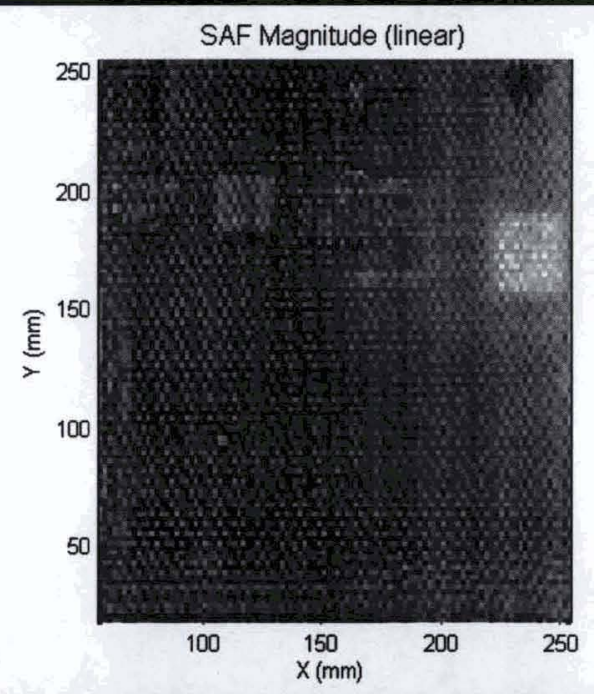

(-42 mm)

SAF Magnitude (linear)

$(-48 \mathrm{~mm})$

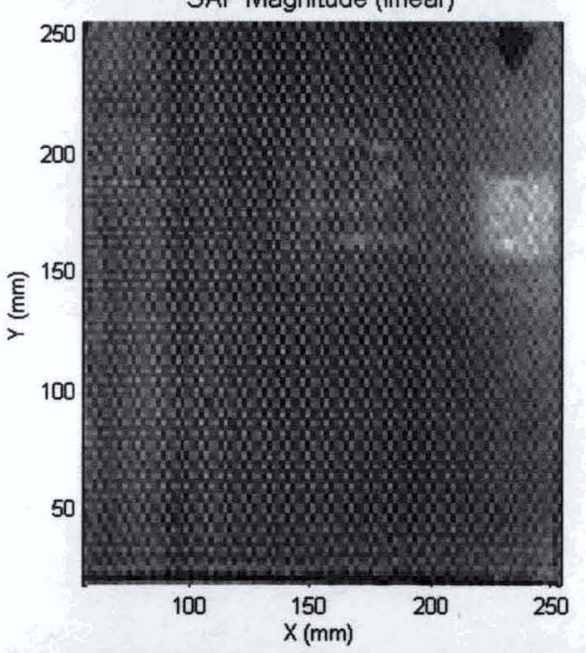




\section{Bomposite Gontrol Surface}
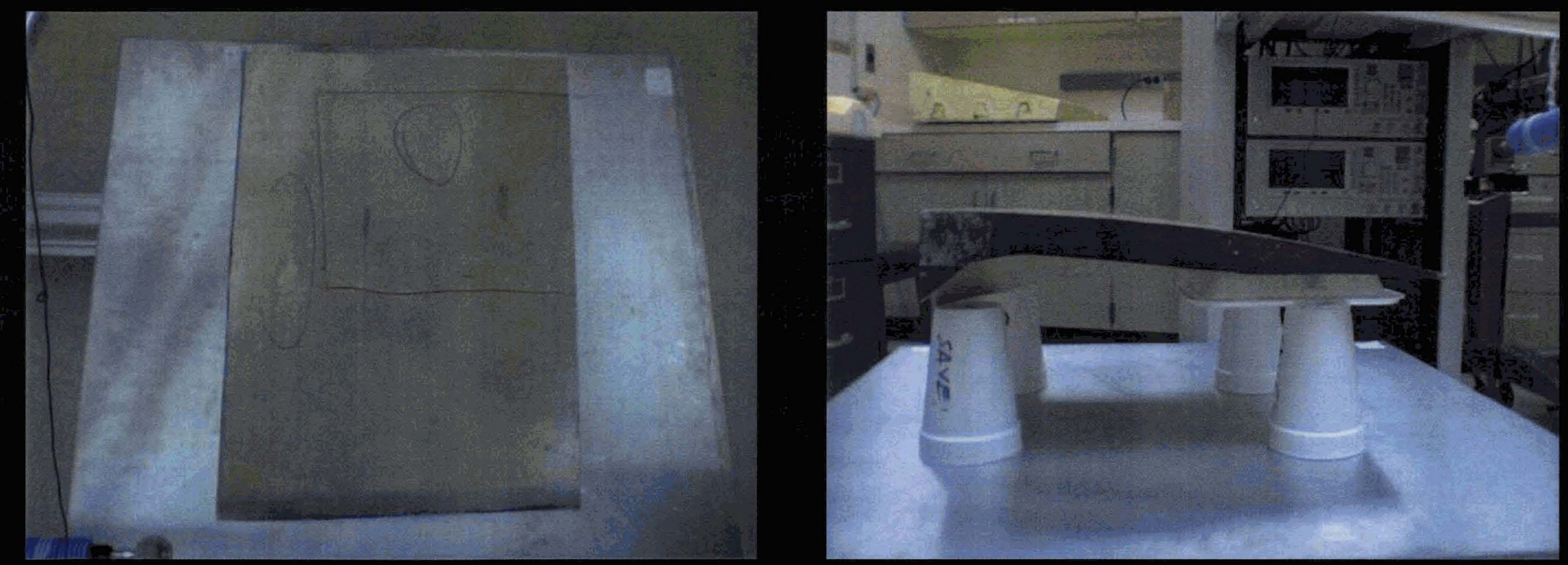


\section{Bolography}

Top View

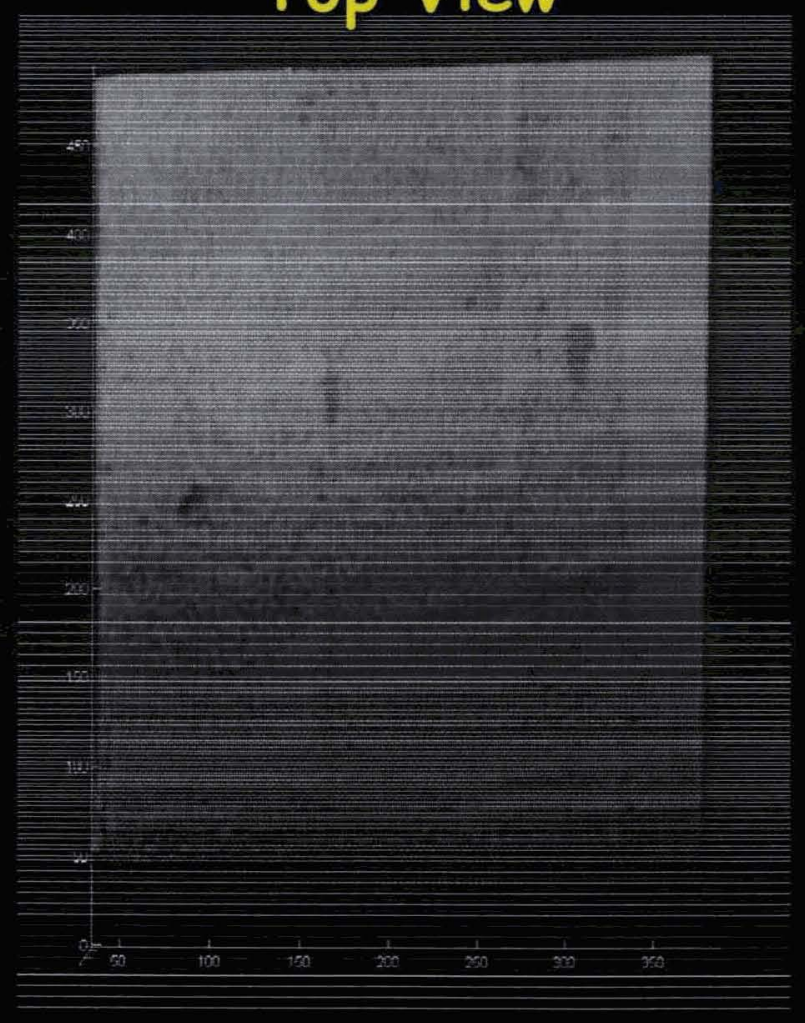

Side View

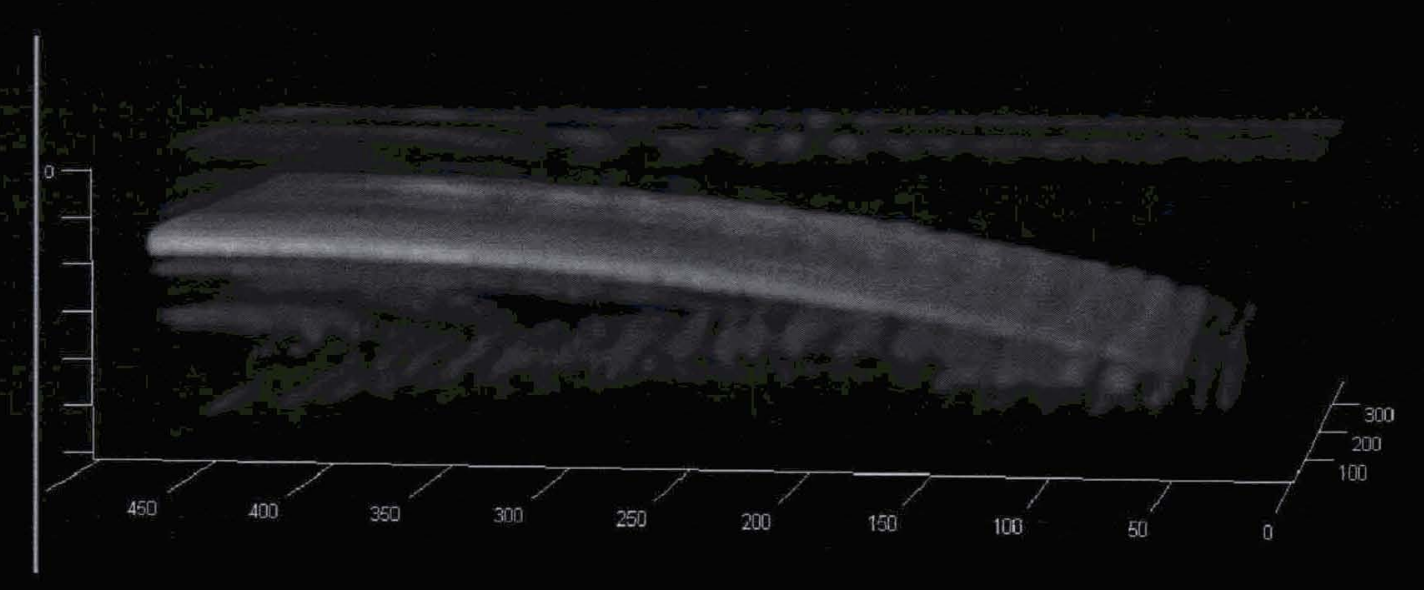




\section{Image Slices}

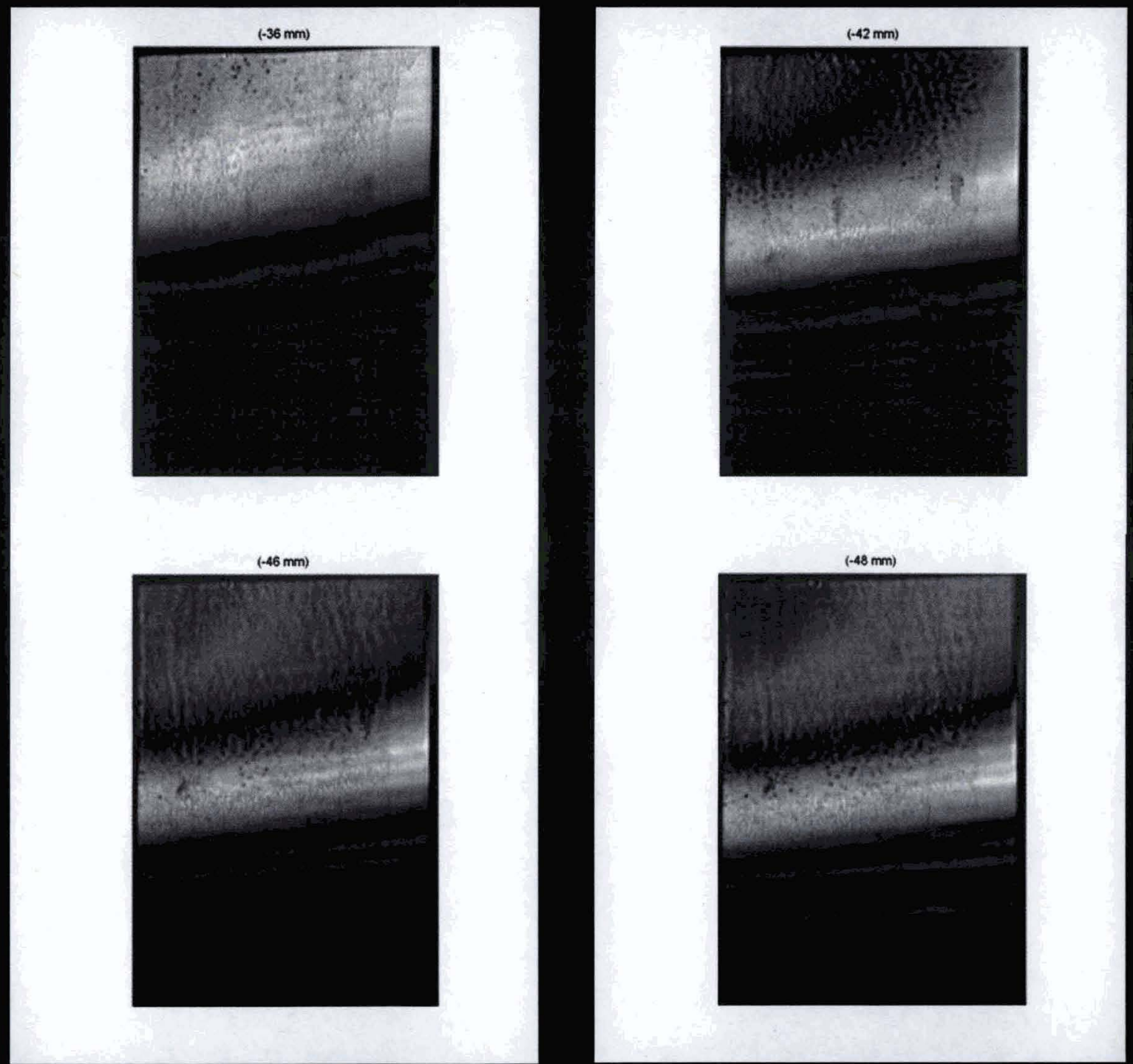




\section{Image Slices}
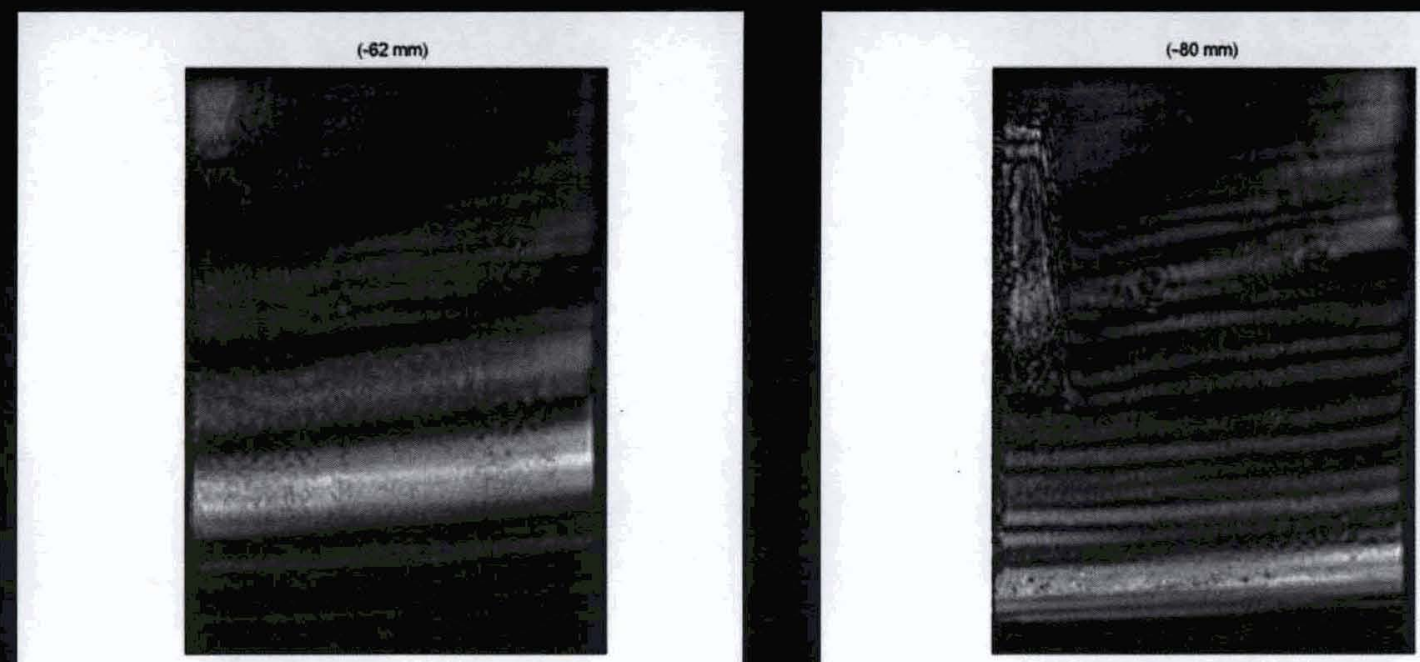

(-92 mm)
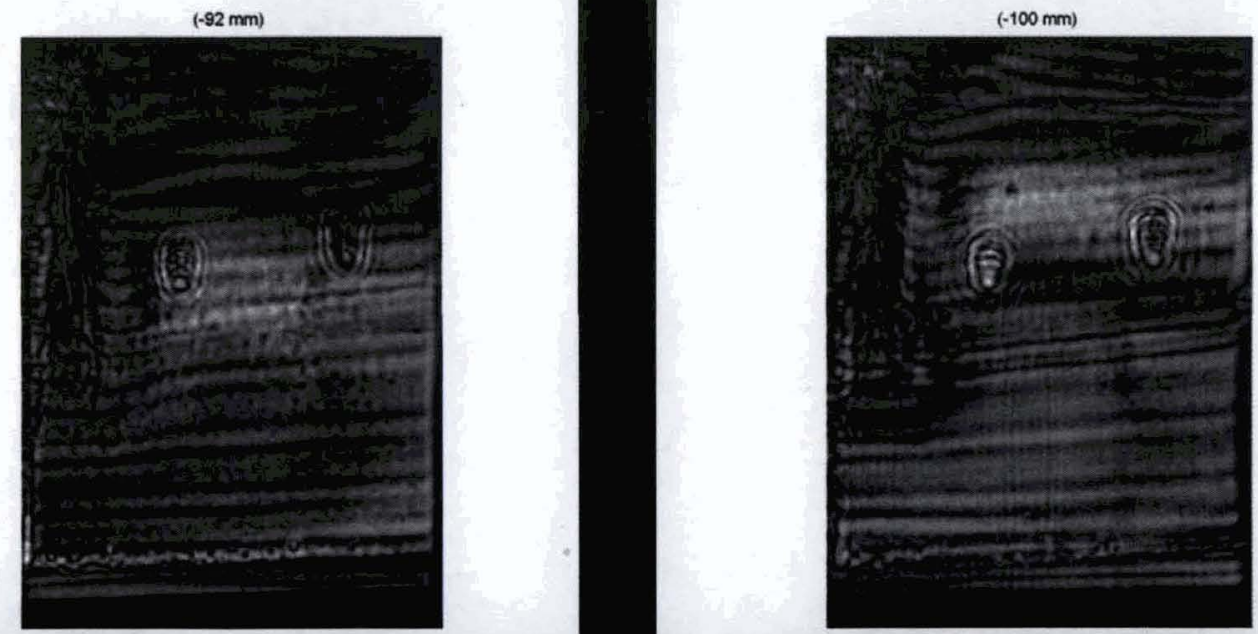


\section{Disenssion}

- Detection of disbond, corrosion, and other anomalies is an important and critical issue with respect to the Space Shuttle health monitoring and other similar space vehicles.

- Real-aperture methods offer high spatialresolution.

Synthetic-aperture methods, in particular a swept-frequency version produces 3D high resolution images with the ability to produce image slices at various depths.

Custom-made systems eliminate need for PNA.

- Scan time may be a practical concern (in some cases). 


\section{Thank You.}

Questions? 